\title{
Creating information literacy partnerships in Higher Education
}

\author{
Clare McCluskey
}

\begin{abstract}
The research reported here focuses on the area of information literacy and its effective embedding within the Higher Education curricula. In particular, it investigates the promotion of partnerships between academic librarians and faculty staff members, with a view to improving information literacy. This area is often seen as problematic due to restrictive structures and ideas about roles, as highlighted in the literature review.

Using the work of Wenger (1998) in relation to the development of communities of practice as a theoretical framework, and an action research methodology (where the ' $\mathrm{I}$ ' is at the centre), the views of academics within one subject area at York St John University have been canvassed via semi-structured interviews, followed up with questionnaires after interventions from the Academic Support Librarian.

The initial interviews showed that the participants held a range of perceptions of the role of the librarian, but that, in the main, they perceived it as a support post. The questionnaires suggested that a group approach, involving several academics and the librarian was more effective in promoting partnership between faculty and library, but that both group and one-to-one interventions had some positive effects in this.
\end{abstract}

\section{The background to this study}

This study takes place in a small Higher Education Institution with four academic faculties and a library service contained in a directorate for learning development. Each faculty is assigned an Academic Support Librarian, responsible for liaising on matters of resourcing and information skills. The Academic Support Librarian and faculty members in this research concern the largest of the four in terms of student numbers, covering both traditional academic subjects and vocational ones.

Until recently information literacy has tended to focus on traditional forms of library instruction, whereby the librarian would offer an induction session in the

\footnotetext{
Author

Clare McCluskey BA (Hons) MSc PGCert MCLIP FHEA is Academic Support Librarian for Education and Theology at York St John University, UK.

Email: c.mccluskey@yorksj.ac.uk
} 
first week of term, with the expectation that students would seek further help as needed. With change in student experiences and expectations in relation to information searching and researching (due to a rise in fee paying, for example), and also the rise in the number and varying quality of online resources, this approach has needed revising, to ensure students are using the most appropriate tools for their research throughout their courses. Not only do users feel that library systems are outdated, with interfaces that are less intuitive than those of Google or Amazon, they do not see that there is a need to use them (Lombardo and Miree, 2003; Herring, 2008). This issue is highlighted from the academic's point of view by Brabazon $(2008,48)$, who describes "a flattening of expertise, knowledge, writing, reading and scholarship" in relation to the "Google effect".

It was therefore the aim of the library at York St John University to embed information skills sessions into the undergraduate curricula of all programmes. Although this had been sanctioned by committees at the higher management level of the University, it was apparent through audits that many courses did not have the level of provision outlined in the strategy.

It was also apparent that some students needed extra help with information searching skills. They were approaching the library for help and showing a lack of understanding about the entire information searching process or what the library could offer to assist. For example, asking for assistance with access to information on the topic of literacy amongst boys in primary schools. When shown search strategies and asked what it was they wanted to find, in order to discern the most appropriate search tool, the response was confusion. There was little consideration of the various types of information available, with the main focus upon journal articles as this was considered to be vital according to tutors. It was the library's view that students should be empowered with the ability to enquire independently, without relying upon the services of a librarian.

The heads of programme within one subject area had previously been approached about how library input could be made more appropriate for their courses and students and an enthusiastic response received. However, this was not translating into fully embedded sessions on the main undergraduate courses. Where sessions were embedded, follow up information suggested that the students were not getting the full picture of how the librarians could assist in developing research and information skills.

For example, a group of students reported that their tutor had recommended that the librarian could help them find e-journals. This is confusing as the library can assist, but it is only one pillar ("locate and access") from the seven outlined by the SCONUL Advisory Committee on Information Literacy (1999). It must be asked whether this is indeed what the academics have asked, or whether they intend for the librarian to show the students the skills required for locating and evaluating information too. If it is what the academics have requested, is the institution not developing independent information skills sufficiently? 


\section{Research question}

The research question is "How do I evaluate the views of the academics in one subject area in regard to my role and investigate ways of promoting partnerships between academic support librarians and faculty members?"

To address this question, it is necessary to break it down into different aims. This particular study is concerned with two possible roads for communication:

Are one-to-one conversations between faculty members or group-based sessions run by librarians for tutors more effective for improving knowledge and sharing of the roles of those from each area?

Two approaches were compared - one-to-one conversations between librarian and individual faculty members and group interactions with two or more academics. Investigations took place to ascertain whether either had an impact on the level of collaboration achieved between tutors and librarians. As shown in the theoretical influences section, the ideal is to have mutual engagement, i.e. a partnership where each others' professional judgement and knowledge is acknowledged and utilised to formulate, in this case, curricula within which information literacy is embedded.

\section{Theoretical influences}

Aligning the research with the concept of social justice in education, a commitment to ensuring that all those involved with the process of promoting information skills are working as a team, with respect for each other, as in the model produced by Chapman and West-Burnham (2010) is key. They assert that it is, "critical for each other to know what other team members gain from participation... plans are shared and contributions are appreciated" (Chapman and West-Burnham, 2010, 132). Reflecting upon this concept, it is possible that effective communication between the library and the faculty was lacking, without concern for the aims and values of each area. Wenger's (1998) concept of communities of practice provided another influential theoretical framework for further investigation.

Wenger asserts that learning is a fundamentally social phenomenon and that mutual engagement is key to this:

Practice does not exist in the abstract. It exists because people are engaged in actions whose meanings they negotiate with one another... Membership in a community of practice is therefore a matter of mutual engagement.

(Wenger, 1998, 73)

This is a view complemented by Chapman and West-Burnham, who also consider the barriers in achieving this outside the usual professional community:

It is relatively easy to share dreams and visions with colleagues who are friends and have similar ideas. However, working with those who have very different visions demands different skills, including confidence in one's own ideas and an ability to accept the perspectives of others.

(Chapman and West-Burnham, 2010, 138) 
Given that previous, "top-down" strategies had not led to embedded information skills, Wenger's concept of mutual negotiation allows for an alternative approach. These two theoretical influences also tally with my own personal values of cooperation, cross-curricula understanding and respect, which are important given the action research approach I have taken, whereby the researcher is at the centre of investigation.

The initial phase involved collecting information about how a good partnership is formed from a tutor with whom a partnership was already developing. Over one year information skills provision had increased from no contact between librarian and academic to embedded sessions on a key MA programme and input on resources at each stage of the validation of future programmes of which the tutor in question was in charge. A meeting was recorded where the development of the relationship was explored.

The tutor expressed the opinion that research into library-faculty collaboration was important and highlighted two important "keys" to the progression of the partnership; being aware of the strengths each party can bring and keeping the dialogue going:

we're moving in the same direction which is important... when you emailed me about partnership I was thinking one the key things is conversations like this and just keeping in touch I think... which I don't think we've done so well in the past but we do much better with you..., not just after, but before validation then following up after validation and just keeping you more involved as well. Not just passing on a reading list... It's win win isn't it? In the past we've been in danger of just seeing you as the person who orders the books. Now it's more of a professional dialogue.

(Tutor G, 2010)

\section{Literature review}

The main focus of the literature review was in the area of partnerships between academics and librarians in Higher Education, with a view to promoting crossdepartmental working and embedding information skills. The key references were found in library and information science databases (LISTA, LISA and Emerald), with only two articles retrieved from the main education resource searched (British Education Index).

A number of articles focus upon the promotion of library services, rather than encouraging the partnerships, and therefore communities of practice, that this study is interested in. For example, Crawford (2009) describes how a liaison role was developed from scratch and details individual initiatives to promote the library to faculty, such as the creation of web pages, interactive tutorials and addressing school councils. However, the views of the academics are not considered - the promotion methods seem to be taken solely from the librarian point of view. Donnelly et al (2006) talk about promoting information literacy tools to the institution's business school. These tools were based on a student survey, but did not take into account the academics' views. Taking the 
approaches outlined in the "theoretical influences" section as a guide, this would not help in creating effective co-operation.

Further literature outlines successful projects in embedding information skills in curricula, but these accounts commence further in the process, with the result that the important issue of how a partnership was set up is not described. Gibson and Luxton (2009) give such an account, based in a BA Education Studies degree, commencing by outlining the embedding of a two hour library session in a first year core module, but not explaining how this point was reached. An account is given of how the partnership developed, with feedback from programme meetings leading to further sessions embedded at all levels of the course. This led to a shift from a focus on how to access resources towards critical thinking about the information searching process on the part of the students and also shifted their perceptions of the librarian, viewing her as part of the academic team, lining up with the ideal conditions outlined in the theoretical influences. There was also a:

change in academic staff's perception of the subject librarian's role from that of a separate persona to an equal and essential partner vital to the student learning experience and programme effectiveness.

(Gibson and Luxton, 2009, 43)

The authors advocate librarian involvement at curricula level, but again omit to say how they got there.

The author with the approach most applicable to this study (i.e. investigating partnerships) was McGuinness (2003). This research asserts that an understanding of roles is needed for effective collaboration, supporting the approach in this study. From this viewpoint, the importance of the perspective of academics becomes apparent, especially in the following ways:

1. Lecturers exercise... autonomy over curriculum content

2. Academics are perceived as the gatekeepers to undergraduate education

3. Little (has been) written about academics' perceptions and attitudes towards

IL

4. Most of what is written is from the LIS perspective

5. Assumption amongst LIS professionals that... integration of IL into teaching curricula is the optimum way to ensure that students become information literate... examples of successful initiatives are comparatively rare... blame laid... on the shoulders of academics.

(McGuinness, 2003, 244-245)

This research involved a qualitative study in which 20 academic lecturers were interviewed about their contact with the library and found that it was generally infrequent and functional (e.g. book ordering), with the librarian as a reactive service provider:

None of the participants discuss curriculum related matters, such as course design or teaching strategy, with library staff, nor do they involve them directly in any of their courses.

(McGuinness, 2003, 249) 
The conclusion of this study gives conflicting messages, firstly saying that: While the majority of participants agree that librarians are teachers - of library skills - they also believe that students do not receive adequate training in this area, and that this is as a result of their own inattention to the problem.

(McGuinness, 2003, 252)

Yet, they are loath to share the classroom and allow the professionals in the information arena to work in partnership with them to address this. This study appears to back up the case for a project which focuses upon the academics' views of the role if the librarian, rather than accounting for their current relationship with theirs.

Later work by McGuinness (2007) looks at specific strategies for integrating information literacy, asserting that the most popular way is using common problem areas (e.g. plagiarism) as a way in. However, the assertion is that this is not the most effective. Ad hoc sessions get librarians on the curriculum, but this does not help to alter perceptions of the role or the power balances involved, thus not providing a strong foundation. McGuinness views co-operation as the best level of partnership, with an "academic champion" who can relate to the students' struggles in information searching and realises that one cannot simply "pick up" information searching skills. An interest in pedagogy is also valuable in order to make the most of information literacy instruction, with a strategic approach to instil an information literate culture advocated as the ideal.

Stubbings and Franklin (2006) assert the need for liaison at the lower level. On a micro level, librarians need to know how to foster good partnerships with as many academics in faculty as possible, to inform the types of strategy advocated by McGuinness (2007). Hardy and Corrall (2007) address the subject of communication and liaison in the context of the changing role of subject librarians, charting the rise of information literacy and the changing role aligned to that. Regarding communication, this research also finds a lack of literature in recent times in the review, but do find mention of a need for more pro-active liaison. The findings on communication saw librarians sitting on departmental committees, using email to liaise, and face-to-face in faculty on a one-to-one basis. The importance of informal contact is also emphasised. Again, there is not much consideration of the best way of initiating liaison, nor how much effect it has on information literacy programme implementation. One of its recommendations for future research is:

perceptions of the role (of the support librarian) and its value held by key stakeholders, such as library directors, academic staff and students.

(Hardy and Corrall, 2007, 89)

The importance of not just imposing the library view of information literacy upon academics is again brought out by Webber, Boon and Johnston (2005), who investigated the conceptions of academics regarding this. They conclude:

some surveys of academics' use (or non-use) of electronic journals, databases or subject gateways have made academics sound like naughty children who are wilfully refusing to use these nice electronic goodies. Rather than trying to 
measure academics' level of information literacy against some generic standard, it makes more sense for librarians... to engage with the language and social discourse of the discipline, in order to create more effective working relationships with academics... It also makes sense for everyone... to reflect on their own conceptions of information literacy.

(Webber, Boon and Johnston, 2005, 14-15)

As outlined in the theoretical influences section, it is my belief that shared plans and respected contributions amongst members of different "professional groups" are vital in establishing effective communities of practice. If these are to be encouraged for information literacy, these beliefs must inform the research and avoid the pitfalls that these authors warn against.

\section{Methodology and methods employed}

The literature review provided evidence of different approaches to embedding information literacy in Higher Education programmes. It has also shown that there is little published on how best foster these. Different studies have proffered suggestions for the level at which partnerships should be fostered and various "hooks" for information literacy instruction put forward. Considering the scale of this project and what was achievable at the level of Academic Support Librarian in the institution in question, the focus fell upon the academics' view of the role of the librarian in one subject area. Interventions were then compared to see if they had an impact upon these views through follow up questionnaires.

The methodology used was an action research one. Action research is a method promoted for those trying to influence their own practice, rather than the traditional, empirical approaches which put the researcher external to events:

In traditional forms of research - empirical research-researchers do research on other people. In action research, researchers do research on themselves. Empirical researchers enquire into other people's lives. Action researchers enquire into their own.

(McNiff, 2002, 6)

As a key concern was improving my own practice, to interrogate what I did with a view to improving it, this was an appropriate approach. It is also an approach which allows the values of the researcher to take an important part in the process as outcomes are validated against these (McNiff and Whitehead, 2006). In this case, my values are of co-operation, cross-curricula understanding and respect, linked to the theoretical influence of social justice in education.

In action research, one identifies an area of practice which requires improvement, then imagines a solution, tries it out and reflects upon the results (McNiff, 2002, 7). In this case the area of practice is the developing of partnerships, specifically focusing on the view of my role as a librarian, related to $m y$ values as outlined earlier. The possible solutions involved interactions with members of the faculty (either one-to-one or in groups) - with the aim of discovering whether one of these approaches was more effective than the other, informing future practice. 
Action research treats issues of bias in a different way to traditional, empirical approaches and this study must be viewed as such:

Action researchers... study themselves, seeing themselves as connected with everyone and everything else. The 'I' studies the 'I' in company with other people... they influence the development of new open thinking and practices that carry hope for the future.

(McNiff, 2010, 29-30)

Given this "I" based approach, it is important in action research to ensure that outcomes are measurable: "What kind of evidence can I gather to show that I am having an influence?" (McNiff, 2002, 14) and that it is demonstrated that learning has taken place, therefore outlining the individual methods used is important.

The first method employed was the semi-structured interview, to gain data on how the academics perceived the role. Following one-to-one interactions with half of the participants and a group interaction with the other half, emailed questionnaires were used to ask if views of my role had changed as a result of the interaction, thereby generating evidence to show if either interaction had been effective.

There are 20 academics working on the programmes associated with this subject. All of these were approached, to see if they were willing to take part in the study and 10 agreed. Four did not then respond to the follow up appeal for interview dates, leaving six.

The approach to interviewing used was emotionalist; generating data to find out about the subjects' experiences (Silverman, 2001, 87). As prior experience of working with this group of people was apparent, knowledge had been gained of the social context of the group, as outlined in the previous sections. Semistructured interviews suit the method of initial data gathering, as a general view of the opinions of the academics in relation to the librarian role could be gathered without being influenced adversely by the interviewer. Rather, in the spirit of the whole project, a partnership experience from the outset was fostered. As Cousin $(2009,73)$ points out, the semi-structured interview is "best conceptualized as a 'third space', where interviewer and interviewee work together to develop understandings". As such, an active, or semi-structured, approach was appropriate because further understandings could be gathered through them, rather than just gaining information to further the established view in library services.

During the interviews, the following questions of the academics in the Education area were asked:

- What do you think the activities I carry out over the academic year are?

- What do you think my priorities are?

- What are my responsibilities?

In asking questions such as these, the views of the academics could be gained without asking directly what the librarian's role was and inducing undue pressure. These questions were designed to tease out prior experiences. The questions also allowed the interviewees to put forward their own ideas for working with the library, especially when it came to the area of priorities. 
Once the interviews were complete, follow up sessions were arranged; one-to-one with half of the sample group and a group session for the remainder. The content of these sessions was an outline of what the Academic Support Librarian can offer and an introduction to the main points of information literacy, followed by a couple of examples of programmes where information literacy is embedded. The academics were encouraged to say how they would like to see information literacy provision implemented for their students. This follows best practice outlined by Hepworth and Walton (2009) for getting groups to reflect on their information skills.

Upon completion of the interviews, brief questionnaires were employed, to determine how (or if) the intervention put in place had changed their views of how the Academic Support Librarian could help students in regard to information skills. Questionnaires were the most practical option to gain further data from the participants at this point in the study; it had proven difficult to arrange two sessions with each of them and, in the summer months when many academics take research leave, carrying out more interviews was not a practical avenue to take. This also allowed triangulation of the evidence found in the literature and the semi-structured interviews, as Gillham asserts:

(a) multi-method approach to real-life questions is important... one approach is rarely adequate... if the results of different methods converge... we can have greater confidence in the findings.

(Gillham, 2007, 2)

The questions in the questionnaire were as follows:

- I have changed my view of Clare's role as an Academic Support Librarian as a result of the meeting(s) I have had with her since the initial interview. (Scale of 1 to $4-1$ not at all, 2 a little, 3 quite a lot, 4 considerably)

- I have new ideas about information skills and the value the library can add to my courses as a result of these meetings.

(Scale of 1 to $4-1$ none, 2 one or two, 3 a few, 4 lots)

- If you have found this process useful, please give up to three examples of ways in which this is the case:

- Any other comments?

The questionnaires were deliberately short, but with an open ended question to gain "a greater level of discovery" (Gillham, 2007, 5). It was important to the partnership building process that the discovery of whether the interventions had been effective was not the only focus, but also why and to try to find out where future efforts should be targeted. The open ended question answers could also be analysed using the same logic as the coding for the interviews, to detect if the respondents had developed their thinking.

\section{Data analysis}

The transcripts of the initial interviews were coded, to identify the type of role the academics thought the Academic Support Librarian had. Words and phrases that 
indicated one of three role types were picked out of each interview; reactive, supportive and equal partner.

\section{Reactive}

Examples of reactive responses:

- "finding out from us what texts we need"

- "keeping us up to date with the budget and what we've been ordering"

- "the library is a tool for my own purposes"

These are reactive as there is not an acknowledgement of the librarian's professional expertise in identifying appropriate texts; it is purely doing as the academic asks.

\section{Supportive}

Examples of supportive responses:

- "Anything I've felt I needed support with, I could come to you and ask."

- "looking at the documentation...core texts and making them more accessible";

- "make yourself available for individual students for extra help";

- "we put across confidence together".

The librarian's professional expertise is taken into account, but the role is still described as supporting, rather than informing, the academics' wishes and waiting to be asked to do something rather than automatically being involved.

\section{Equal partner}

Examples of partnership responses:

- "the key thing is that they see our joined up thinking";

- "you and the module director (should have)...a clearer understanding of what we want from our students";

- "we can help the students develop their own lines of enquiry".

The librarian is involved at a strategic, curriculum level.

The outcomes for each interview were as follows:

\begin{tabular}{|l|l|l|l|}
\hline & Reactive & Supportive & Equal partner \\
\hline Tutor A & 6 & 5 & 0 \\
\hline Tutor B & 1 & 7 & 7 \\
\hline Tutor C & 0 & 8 & 7 \\
\hline Tutor D & 1 & 6 & 7 \\
\hline Tutor E & 0 & 8 & 10 \\
\hline Tutor F & 0 & 7 & 0 \\
\hline
\end{tabular}

Table 1: Outcomes of semi-structured interviews 
From this, it is apparent that one academic saw the role as predominantly reactivesupportive, one entirely supportive, two mostly supportive, with some tendencies to partnership and one leaning towards partnership more strongly.

In regard to investigating how best to promote partnerships between the faculty and the library, it is worth noting that staff development for faculty members on information skills was asked for by four of the six interviewees and a fifth requested more updates in terms of new developments from the library. The only interviewee who did not request this was the one who saw the role as reactive. Time pressures and not knowing how to gain access to development were commonly stated as reasons for staff development not being easy to access.

This aligns with the experience of carrying out this research project. Organising the one-to-one follow ups was much easier than organising a group session that more than two people could attend, due to timetabling and course commitments.

The results of the closed, multiple choice questions on the short questionnaire indicate that each method had some effect.

\begin{tabular}{|l|l|l|l|}
\hline & Intervention & $\begin{array}{l}\text { Perceived change } \\
\text { in my role- } \\
\text { response }\end{array}$ & $\begin{array}{l}\text { New ideas about } \\
\text { information skills- } \\
\text { response }\end{array}$ \\
\hline Tutor A & One-to-one & 2. A little & 2. One or two \\
\hline Tutor B & Group & 3. Quite a lot & 2. One or two \\
\hline Tutor C & Group & 2. A little & 4. Many \\
\hline Tutor D & One-to-one & 3. Quite a lot & 3. A few \\
\hline Tutor E & One-to-one & 3. Quite a lot & 3. A few \\
\hline Tutor F & Group & 3. Quite a lot & 4. Many \\
\hline
\end{tabular}

\section{Table 2: Outcomes of questionnaires}

This evidence suggests that each intervention was equally effective in changing the academics' views of the Academic Support Librarian's role and that the group intervention was more effective in providing more ideas for information skills in the curriculum than one-to-one, although both methods had something to offer in this area.

The answers to the open ended questions also indicate that a shift in opinion has taken place. Tutor A was classed as 'reactive-supportive' after the first interviews, but states in the questionnaire that he now realises that:

Clare is being proactive in the support she can offer... we both want the same things in terms of how we want the students to make use of the library.

(Tutor A, 2010)

Tutor D, who was classed as "tending towards partnership", but with many views of a supportive nature initially, now approaches the interaction from even more of a partnership angle:

Previously I thought that librarians sat in the library and ordered books for our programmes. They were not visible to tutors and only supported students when 
asked individually. I have been positively enlightened by the more open and supportive approach of Clare, which values tutors and students alike. I think it is essential that this open collaboration continues, rather than be seen as conclusive in its own right.

(Tutor D, 2010)

Returning to my values of co-operation, cross-curricula understanding and respect, this extract shows that this relationship has moved considerably more towards partnership and goes towards creating a community of practice in relation to information skills. Rather than being focused upon an end product of an embedded information skills session, both faculty and library are reflecting upon and valuing each others' expertise in improving the critical engagement of the students and members of staff alike.

\section{Conclusion}

The study set out to discover two main things: to evaluate the views of the academics in one subject area in regard to my role and to investigate ways of promoting partnerships between academic support librarians and faculty members, as influenced by the concept of communities of practice.

As this was a small scale study, a $30 \%$ participation rate should be sufficient to evaluate the research question in this instance, as it also included representatives of heads of programme, module leaders and course tutors without responsibility for modules. However, the evidence gathered must be viewed in the light of a small sample and as providing the basis for further investigation.

The interviews indicate that there is a spread of views about the Academic Support Librarian role, but that, in the main, it is one of support, with some tending to perceive it as more reactive and others viewing it as a partner. It would be valuable to follow up these interviews with more academics across this subject area and beyond, across the faculty, to ascertain whether this is indeed representative of the academics or whether this small sample refers only to those who chose to take part in the study.

The interviews also raised a key issue which needs tackling from the point of view of the library; that many academics feel they need more staff development themselves in the area of information skills, before they are confident in progressing to embedding them in the curriculum. This is something to address in the near future.

The one-to-one and group sessions were very productive in building upon the relationships established in the interviews. Firm plans were made with each of the tutors regarding how information skills could be embedded in their courses in the new term. These varied from simple input in the Virtual Learning Environment, to being a part of the module team, but each was a step forward from the previous year.

Regarding the best form of intervention for promoting the embedding of information skills, this group is too small to come to any firm conclusions. The questionnaire indicates that the group intervention may just be more effective, but 
this was also the more difficult to arrange. It took time to arrange group meetings and would have been more efficient to arrange one-to-ones with each individual. Nevertheless, the responses do indicate that making the effort to provide such discussion fora could lead to greater understanding and potential for working in partnership in regard to information skills.

\section{References}

Brabazon, T. (2008) As a seagull to chips. Library and Information Update, (Oct), 48-49.

Chapman, L. and West-Burnham, J. (2010) Education for social justice: achieving wellbeing for all. London: Continuum.

Cousin, G. (2009) Researching learning in higher education. New York:

Routledge.

Crawford, A. (2009) Academic liaison librarians - where do we stand: a personal view. SCONUL Focus [online], (45), 34-37. URL:

http://www.sconul.ac.uk/publications/newsletter/45/ [accessed 7.12.09].

Donnelly, K. et al (2006) Blended learning in action: the Infoskills programme at Manchester Metropolitan University's Library Service. New Review of Academic Librarianship, 12 (1), 47-57.

Gibson, S. and Luxton, J. (2009) Departure from the library desk: one undergraduate programme's story of its subject librarian's evolving role.

SCONUL Focus [online], (45), 41-44. URL:

http://www.sconul.ac.uk/publications/newsletter/45/ [accessed 22.5.09].

Gillham, B. (2007) Developing a questionnaire. $2^{\text {nd }}$ Ed. London: Continuum.

Hardy, G. and Corrall, S. (2007) Revisiting the subject librarian: a study of

English, Law and Chemistry. Journal of Librarianship and Information Science, 39 (2), 79-91.

Hepworth, M. and Walton, G. (2009) Teaching information literacy for inquirybased learning. Oxford: Chandos.

Herring, M. (2008) Fool's gold: why the Internet is no substitute for a library. Journal of Library Administration, 47 (1/2), 29-54.

Lombardo, S. and Miree, C. (2003) Caught in the Web: the impact of library instruction on business students' perceptions and use of print and online resources. College and Research Libraries [online], 64 (1), 6-21. URL: http://www.ala.org [accessed 14.8.08].

McGuinness, C. (2003) Attitudes of academics to the library's role in information literacy education. In: Martin, A. and Rader, H. (eds.) Information and IT literacy: enabling learning in the $21^{\text {st }}$ century. London: Facet. 244-254.

McGuinness, C. (2007) Exploring strategies for integrated information literacy: from academic champions to institution-wide change. Communications in 
Information Literacy [online], 1 (1), 26-38. URL:

http://www.comminfolit.org/index.php/cil [accessed 14.12.09].

McNiff, J. (2002) Action research for professional development: concise advice for new action researchers [online]. URL:

http://www.jeanmcniff.com/Copy\%20booklet\%20for\%20web\%20site.doc [accessed 7.1.10].

McNiff, J. (2010) Action research for professional development: concise advice for new (and experienced) action researchers. Poole: September Books.

McNiff, J. and Whitehead, J. (2006) All you need to know about action research. London: Sage.

SCONUL Advisory Committee on Information Literacy (1999) Briefing paper: Information Skills in Higher Education [online]. London: SCONUL. URL: http://www.sconul.ac.uk/groups/information_literacy/papers/Seven_pillars2.pdf [accessed 27.5.09].

Silverman, D. (2001) Interpreting qualitative data: methods for analysing talk, text and interaction. $2^{\text {nd }}$ Ed. London: Sage.

Stubbings, R. and Franklin, G. (2006) Does advocacy help to embed information literacy into the curriculum? A case study. Italics [online], 5 (1), 1-11. URL: http://www.ics.heacademy.ac.uk/italics/vol5-1/pdf/stubbings-franklin-final.pdf [accessed 27.5.09].

Webber, S., Boon, S. and Johnston, B. (2005) A comparison of UK academics' conceptions of information literacy in two disciplines: English and Marketing. Library and Information Research, 29 (93), 4-15.

Wenger, W. (1998) Communities of practice: learning meaning and identity. Cambridge: Cambridge University Press.

\section{Open access and copyright}

Library and Information Research is an open access journal. A freely available copy of this paper may be downloaded from the journal's website: http://www.cilipjournals.org.uk/lir

Copyright and associated moral rights in works published in Library and Information Research are retained by the author(s) but this paper may be used freely, with proper attribution, in educational and other non-commercial settings. 